COMMENT

DOI: $10.1057 /$ s41599-018-0179-4

\title{
Kick the hive, get the bees: graffiti writers as assemblage and direct action political actors in their battle against $H \& M$
}

Tyson Mitman ${ }^{1}$

\begin{abstract}
In October of 2017 fast fashion retailers H\&M produced an online ad that featured some of Jason 'REVOK' Williams' graffiti in the background. Revok filed a cease and desist order to get H\&M to stop using his work in their ad. H\&M then sued him, claiming he had no right to copyright protections because the work was produced illegally. This lawsuit became public knowledge and infuriated the global graffiti community, who began a week long worldwide uncoordinated direct action campaign against H\&M. Graffiti writers wrote graffiti on H\&M storefronts and ideologically attacked $H \& M$ in social media spaces until the lawsuit was dropped. This article will examine why graffiti writers responded to the lawsuit against Revok this way, considering these graffiti writers had to undertake great personal risk to commit their acts of vandalism and, because none of them had any personal or financial stake in the outcome of the lawsuit. To understand why graffiti writers acted as they did graffiti as a protest act and as a spectacle will be discussed, as will the importance of subcultural capital. Further this article will explain the motivations of graffiti writers in their fight against H\&M and the ways that they use physical and virtual spaces to build their reputations and interact and communicate with each other. Ultimately, this will explain how H\&M filing the lawsuit against Revok provided a crucial moment of opportunity that allowed graffiti writers to engage in dramatic public acts of self-promotion. These acts marked writers as politically aware, antiauthoritarians willing to take risks and violate the authoritative aesthetics of the clean and controlled H\&M storefronts in support of Revok, which in turn made their acts of graffiti forms of contentious political participation. Through sharing their acts on social media and associating it with the Revok vs. H\&M conflict through hashtags, writers further promoted themselves, clearly associated themselves with famous graffiti writer Revok and increased their general presence and their subcultural capital within the graffiti community.
\end{abstract}

${ }^{1}$ York St. John University, York, UK. Correspondence and requests for materials should be addressed to T.M. (email: t.mitman@yorksj.ac.uk) 


\section{The situation}

$\mathrm{n}$ October of $2017^{1}$ fast fashion retailers H\&M produced an online ad for their newest active wear line "New Routine." In the ad a man dressed in a New Routine t-shirt and shorts runs at a handball court wall in Williamsburg, New York City and does a backflip off of it (see Fig. 1). Painted on the wall is some of Jason 'REVOK' Williams' current street art/graffiti project. The work was painted illegally. Revok never asked permission to produce the work, nor did the New York City Parks and Recreation Department grant permission for the work to remain on the space. Once Revok saw the ad he had his lawyer, Jeff Gluck, send a cease-anddesist letter (dated January 8th, 2018) to H\&M saying H\&M had "included [his] original artwork in an advertising campaign for H\&M products without his permission or knowledge."

H\&M responded by filing a lawsuit (dated March 9th, 2019) against Revok claiming that due to the work being produced illegally and on a public space he had no claim to copyright protection. The lawsuit was shared on social media and the graffiti community reacted with outrage (see Fig. 2) and began hashtag campaigns of, amongst others, \#fuckHandM, \#boycottHandM, \#boycotthm (hashtags cannot include \&) and \#payrevok. Many of these hashtags began appearing on March 14th, 2018 after the lawsuit became public knowledge, though some of them already existed as a protest to the apparent racism of H\&M releasing an ad featuring a black adolescent boy wearing a sweatshirt with the words 'coolest monkey in the jungle' across it.

International retailers and brands like H\&M are keenly aware of the way negative publicity can damage their reputation and how that can translate to revenue loss so they acted quickly. By 4:30 p.m. on March 15th H\&M had released a statement claiming that they respected 'the creativity and uniqueness of artists, no matter the medium.' And that they had dropped the lawsuit against Revok ${ }^{2}$. That was almost immediately followed by a statement from Revok's lawyer saying, 'The lawsuit is not dismissed, and the artwork is even still being used on their website.' By 10:00 p.m. Gluck released another statement saying that the council for H\&M had told him that they were not dropping the lawsuit. However, by 11:20 a.m. on March 16th court records indicated that the case was withdrawn through 'voluntary dismissal.'

It is important that every step of this story played out publicly. Had it not, had it instead been a single retrospective story about how H\&M filed a lawsuit against Revok then over the next two days had it challenged and dropped it, perhaps the reaction of graffiti writers would have been different. But that is not what happened. By March 14th, 2018 it was public knowledge that H\&M had used Revok's work without his permission and were suing him as a response to his cease-and-desist order. This incensed graffiti writers and Revok supporters, who began a direct action campaign against the physical spaces of H\&M stores.

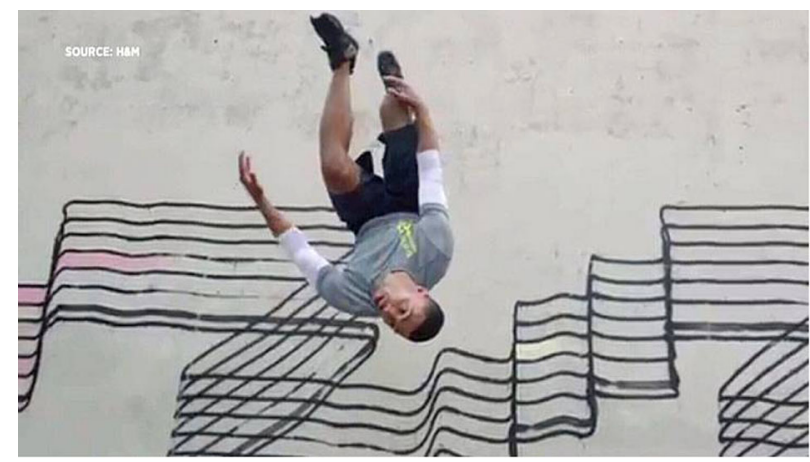

Fig. 1 Still from H\&M's New Routine ad campaign. This figure is not covered by the Creative Commons Attribution 4.0 International License.

Reproduced with permission of H\&M. copyright (C) H\&M, all rights reserved

\section{Graffiti and space}

On the night of Wednesday, March 14th, 2018 writers (graffiti writers typically just call themselves 'writers') SPD and Reave tagged (a writer's stylized signature) the front of the H\&M store in Center City Philadelphia. They tagged the windows and directly over the H\&M nameplate bolted to the building. By the morning of the 15th they had shared their exploits on social media. They were not the only writers busy that night. Many other instances of graffiti against H\&M were posted by March 15th. A video showing writer Hart using a fire extinguisher full of paint to paint a one-story-tall tag on the front of a New York City H\&M store, and a video of the front of an H\&M store in San Francisco with 'Fuck HxM' painted across it both appeared on Instagram. As did an H\&M storefront in New Orleans with 'Pay Revok' painted on its front doors. That Monday (March 19th, 2018) evidence of H\&M stores being vandalized from Paris, France to Chicago, Illinois to Hasselholm, Sweden were shared on social media. Graffiti writers in Dallas, Texas and Bali, Indonesia painted 'Fuck H\&M' graffiti pieces and shared those on social media. All of these posts were liked over and over and shared repeatedly.

By Sunday the 18th though it was common knowledge amongst those who were interested that H\&M had dropped the lawsuit. This seemed to be enough to placate the global graffiti community and the vandalism against H\&M stores, as well as the hashtag campaigns, began to die down. But the series of events that unfolded raises the question of why graffiti writers who had no personal or financial stake in the outcome of the lawsuit against Revok acted as they did. In addressing this question the way graffiti writers think about themselves, how they work to position themselves within the community of graffiti writers, and how social media is affecting this practice will be examined.

Writers understand themselves and what they do in multiple complex and dynamic ways. There is not space for a full discussion here (see Mitman, 2018; Snyder, 2009; and Halsey and Young, 2006; Lachmann, 1988; Castleman, 1984 for further discussion) but in its most basic form what writers seek is recognition through the production of striking spectacles. Principally,

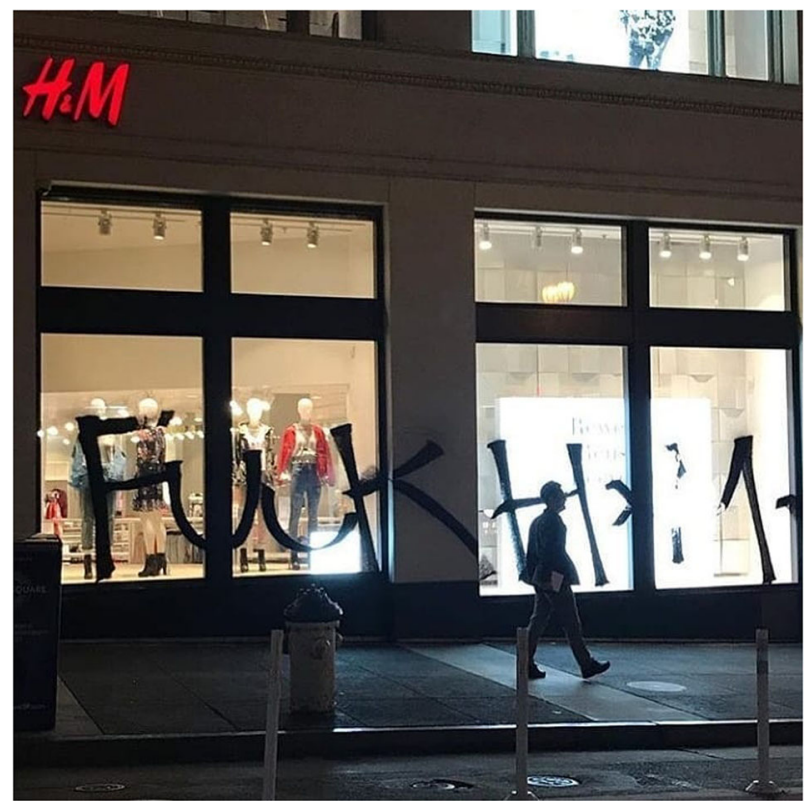

Fig. 2 'Fuck $H x M$ ' spray painted across the front of a San Francisco H\&M store. This figure is not covered by the Creative Commons Attribution 4.0 International License. Reproduced with permission of Instagram user Lokasaysfuccu; copyright (c) Instagram user Lokasaysfuccu, all rights reserved 
writers understand the spectacle as being about how social relationships and social power are mediated through images and how the ability to publicly represent oneself or one's ideas and positions increases one's social power. The way writers attempt to create spectacle and build reputation is by writing their name often, publicly, and in the 'right' places. As such the primary concerns for writers when writing graffiti are the visibility of a space, if that space is an acceptable place to put graffiti as dictated by graffiti's internal guidelines (for a full discussion of these see Mitman, 2018, pp. 59-86), and who is likely to see their graffiti on that space. Simply put, for writers, space matters. Writers use the spaces they interact with to build a reputation, as places of expression, as places of subjective identity production, as a way to access a political voice, as a way to display their anti-authoritarian stance, and as a way to violate, and thus expose, the visual hegemonic order within a space (Mitman, 2018).

In targeting H\&M stores and posting their acts on social media writers engage with all of these spatial uses. They increase their reputations by making their name and presence publicly visible. They increase their subcultural capital, express themselves, and enact their subjective identity simply by writing on the H\&M storefronts. These acts violate the 'aesthetics of authority' (Ferrell, 1996) that exist in those spaces up until writers place their graffiti there. As such, the graffiti helps reveal the present but unstated visual hegemonic order of the space by being an obvious violation of it. Further, by writing graffiti writers affirm their antiauthoritarian position and, by specifically writing on H\&M stores at this particular moment they align themselves with Revok's cause thus making their acts a form of contentious political participation (Waldner and Dobratz, 2013).

However, the global H\&M storefronts that were affected are not the only spaces involved here. The other spaces that need to be considered are the online spaces that these writers' performative actions were shared in, i.e., the social media accounts where they posted what they did. To understand what happened, and the feedback loop between physical and online spaces, we have to understand how writers understand those spaces individually.

\section{Physical space}

As mentioned, one of the ways writers see their use of space is as a way to access political voice. In this case writers are writing as a type of protest action. This can be directly seen in how writers were engaging in contentious political participation by tagging or otherwise writing on H\&M stores specifically to voice their disapproval of the corporation's theft of Revok's work. What is important here is to see that graffiti can serve as a political protest act not for what it says, but for where it is and what it does to the spaces it is on. I have shown that graffiti on abandoned homes can serve as a conscious and unconscious protest against homelessness, poverty, private landlords allowing property to become derelict, and/or gentrification (Mitman, 2018). Graffiti can then sometimes be seen as an effort by writers to have their voice heard in a legal, economic, and political process that has excluded them. Understanding writers as an informed, critical, aware, and assertive group with the potential to deliver a politically charged message allows us to see them as individuals engaged in a type of praxis (Arendt, 1998) and allows us to understand their work as having the capacity to be an emancipatory communicative act (Habermas, 1984) that demands greater participation for writers in debates or decisions that affect them.

Writers tagging H\&M stores are doing just this. They are demanding that their voice be heard, and what they are saying is that they vehemently disagree with the lawsuit against Revok, the unauthorized and unpaid use of his work, and the implication that all graffiti and street art could be subject to the same treatment in the future. It is important to note here that graffiti writers rarely paint corporate storefronts. It is considered a waste of paint, a precious resource for writers. The business will remove whatever the writers have painted as soon as possible, sometimes even before the business opens the next day. Since the public will not see the work, and it is risky to paint these spaces as they are often in heavily patrolled and surveilled business districts, painting them is generally considered a pointless risk and a waste of assets.

But why were writers willing to accept such risks and waste their assets against H\&M? It is not uncommon for graffiti writers' work to get directly appropriated or stolen for use in advertising or fashion (Joseph 'Rime' Tierney's work was stolen by Moschino, Patrick Waldo's work was stolen by Zara, and The Bushwick Collective had their work swiped by McDonald's, just to name a few) and the graffiti aesthetic is frequently taken for marketing purposes with no collective action taken by the graffiti community. What was different about this time? According to the wellknown graffiti writer, entrepreneur, author, and gallery curator Alan Ket the issue is 'not that they stole the artwork, it's that they filed the lawsuit that's really insulting to me' (Ket, 2018).

What Ket is saying here is that the offense H\&M committed was twofold. First, they appropriated Revok's work and second, they filed a lawsuit claiming he had no ownership of it. This attack on any rights Revok might claim to the ownership of the graffiti he produces and how it might be used is offensive enough to infuriate the graffiti community, but writers also inferred from the lawsuit that this was an attack on the copyright protections of all graffiti and street art, and as such was a shot across the bow to all graffiti writers. For those who read the situation like this, picking up the cans to help defend Revok was the obvious choice. Revok is a venerated elder statesman in the graffiti community. Doing something that showed support for him, showed support for graffiti culture in general and directly violated the offending corporate entity was almost certain to cement writers who wrote on H\&Ms as legitimate members within their local scenes and raise their subcultural capital (Thornton, 1996). This is a large part of why writers felt compelled to tag H\&M stores, because doing so attached them to the cause of a renowned graffiti legend, legitimated them as politically aware and aggressive writers, and raised their position within their graffiti communities.

They had to let others know they did it though. And, as mentioned, graffiti on corporate spaces does not stay there very long. Writers are aware of this. So they documented their actions with pictures and videos and shared them on social media. They ensured that those who saw what they did would know that they did it in support of Revok by using the hashtags associated with his cause. In acting this way writers revealed one of the ways they understand virtual space and how they see it linked to physical space.

\section{Virtual space}

Graffiti writers are a diverse and geographically dispersed community. And while local reputation is of crucial importance to them building a standing among a larger, more widely distributed audience is important as well. This is one of the reasons that social media is so popular among graffiti writers. It gives them the ability to share their work with a wider group of interested and like-minded people. This ability to share their exploits with a more globally distributed audience matters in a few ways when it comes to committing direct protest actions against H\&M.

First, it is unlikely that any collective direct action against H\&M would have happened without the ability to use social media to quickly distribute information to a sympathetic group of followers. This ability to access and/or produce a cultural hive 
A threat to artist's rights. Boycott @hm

This week, fashion retailer H\&M filed a lawsuit

in Federal Court in New York, allegedly asking

the court to essentially rule that any and all

unsanctioned or illegal artwork, such as street

art and graffiti, should be devoid of copyright

protection and can be used by any brand or

corporation, without any payment or even

needing the artist's permission. This action

taken by H\&M is a full out assault on artists'

rights and we must raise our voices. This

could render millions of murals and important

pieces of artwork worldwide completely

unprotected and available for corporate use,

without anv navment or nermission needed

Fig. 3 'Boycott H\&M' image, which declares H\&M's lawsuit and 'assault on artists' rights' that was shared repeatedly on social media. This figure is not covered by the Creative Commons Attribution 4.0 International License. Reproduced with permission of Instagram user Insa_gram. copyright (c) Instagram user Insa_gram, all rights reserved. This image is reproduced according to fair use

mind' was crucial to the production of a motivated group of writers who were willing to take Revok's cause to the streets. But equally important was those 'hive' members' ability to feed back to the group, especially its prominent members, by sharing their support, opinions, or actions with them. It is social media's ability to facilitate these kinds of interactions that partially motivated individuals to act against $\mathrm{H} \& \mathrm{M}$ as they did. The idea that a writer could write on an H\&M storefront, share that on social media, and have their post and actions praised and shared by high ranking members of that community, some of whom may have celebrity status, potentially even Revok himself, was a powerful motivator. This form of recognition serves as a powerful type of cultural vetting that reinforces one's position in the community, raises their status, and builds their subcultural capital. Their reputation is increased further when their peers see their post and who liked it or when another community member is introduced to them because of the post (or share, or retweet).

The way in which subcultural groups self-organize in online social media environments is, in its simplest form, by users finding content and other users that they are interested in and creating loose networks around them. Those with a common interest in graffiti create online affinity spaces (Gee, 2005) around their shared interest. These online affinity spaces form via a particular type of semiotic social space (Gee, 2005) where individuals find and follow other users based on those users' reputations, the way they value the content users produce, or the connection they have to a particular user. People also find new content or users that interest them by searching through the networks of the users they follow or through searching the hashtags users use to code their posts and associate them with a certain set of cultural practices or ideas.
Individuals who are interested in graffiti could easily have seen the below image (see Fig. 3) and its 'boycott H\&M' message and began following the hashtag, which then introduced them to new and related hashtags, users, and content. This image was shared hundreds of times (many of those shares by prominent individuals within the graffiti community) and it spread very quickly through the online graffiti and street art affinity spaces. Many people added artwork and commentary (famous artist Kaws contributed a drawing of a tombstone with the H\&M logo on it) to this hashtag and created new ones, but there was no call to direct action against H\&M by Revok or anyone who represented him.

\section{Convergence}

The jump to direct action against H\&M in the form of graffiti is no great stretch though. Revok is a graffiti celebrity, he was calling out to an audience composed largely of graffiti writers and supporters, and it is in the nature of writers to write on physical space and to act against those they view as violating or being oppositional to their interests. What is interesting is the way writers see a dialectical and dialogical relationship between the virtual and physical spaces. Where those spaces comprise each other through the way actions and interactions occur and are constructed within physical spaces, but also through how those actions and identities produced in physical space are received and negotiated in the multiple and overlapping areas that construct the virtual spaces. The way a writer is received in those virtual spaces then affects and influences how that writer sees themselves and how other writers view them. This affects how all of those writers behave in physical space toward each other. This then affects how they position themselves with and around other writers in virtual spaces, and so on in this dialectical manner.

Simply put, writers write graffiti in the physical world within the confines of a certain area, and in that area they create spectacle and build a reputation. What writers are trying to do is create and maintain presence within that space. They achieve this by not having the presentation of their graffiti self derided or challenged, increasing their presence on the streets (having more graffiti work up) and by asserting their reputation as an aggressive, cunning, creative, and skilled writer. If they do these things successfully their position within the subculture is improved.

Many writers use social media as a way to preserve and display their work, increase the audience who sees it, and increase their reputation. Doing this gives them the opportunity to share their work in new ways, but it also deterritorializes their work. When writers share their work on social media the particulars of the area they painted in or the spaces they painted on can get lost. Social media offers writers' ways to compensate for this by allowing them to explain what they went through or connect the work to a larger set of concepts by associating it with established hashtags or by creating new ones. Further, social media allows writers to share their work in ways beyond simply posting an image of it. They can post a video of their finished work and the area around where it is, giving context to it and the risks they had to engage with to put it up. They can record themselves doing the work and show how brazen or crafty or skillful they are. By doing this they can also show how capably they can use their equipment, and subvert security perimeters or surveillance systems to put up their work. Or they can juxtapose before and after images of the space they painted to show how their work affected and altered that space and improved it or disrupted the 'aesthetics of authority' (Ferrell, 1996) within it. They can do all this while providing narration for video and captions to frame their work through their desired subjective identity construction and subcultural position taking. 
All of these components come together to form the way a writer would like to have their graffiti self perceived. This is their style. As Ewen $(1999,79)$ put it, "Style was a way of saying who one was, or who one wished to be." For writers style is a matter of becoming. Through the work they produce, the way they use social media to represent their work and connect it to other ideas and writers, and the way they try to cultivate presence and reputation writers are trying to construct a subjective identity for themselves that reflects their idea of what a graffiti writer is and, more specifically, what it means to them to be a graffiti writer.

Understanding writers this way allows us to see them, and what they do, as a type of assemblage (Deleuze and Guattari, 1987). The idea of assemblage being that bodies within any system are not fixed in position or stable in any position that they might occupy, rather they are dynamic with and among other bodies that exist within the systems they do, and are effected by all of those other systems that may affect the systems that they exist in. Of course, bodies may occupy multiple positions, and positions in multiple systems simultaneously, and they may be completely removed from systems, replaced within them, or constituted within other systems by virtue of their actions or presence within any given system.

Most straightforwardly, writers who use social media are an assemblage of their subjective graffiti selves, which they cultivate in physical and virtual spaces, and the way that participation in these physical and virtual worlds place certain preformative demands on them, which constitute them as well (i.e., to go out and write graffiti and to share that they have done it). First, to become a graffiti writer a person must write graffiti on physical spaces. This is the process through which they begin to construct their graffiti self. This self is composed of how writers understand graffiti history, how well they can produce locally valued graffiti styles, their work ethic, and the way they cultivate and maintain reputation within their subcultural group through how they behave within it. All of these elements come together to reinforce the subjective identity and style of a particular graffiti writer.

Second, when cultivating an online presence for their graffiti self writers are seeking to further the idea of themselves that they are working toward in the streets. As such they must share their work on social media, but do so in a way that reinforces their ideal construction of their graffiti self. Social media affords them the opportunity to do this.

The assemblage then that a writer exists in is one composed of the graffiti writer within and among the other writers in their local scene, the relationships between them, and the dialogical interactions of the physical graffiti they produce among what is already present. Additionally, when writers cultivate a social media presence they engage with online graffiti communities composed of practitioners and fans alike, some of whom are also members of their local communities (graffiti or otherwise). In these online spaces they are able to exhibit their work to geographically diffuse audiences and link it to ideological and culturally significant constructs through their use of hashtags. This extends the communities they participate in and can create overlap between them. It can also create new preformative pressures to paint more graffiti, and can create new conflicts with other writers or social media users. Further, a social media presence can expose a writer to increased risk from authorities and vigilant citizens because a social media account is linked to a person in a way a name on a wall is not. Ultimately this means that a writer who posts their work on social media participates in, and becomes part of, an assemblage of their local graffiti self, their representation of self cultivated on social media, the way their local graffiti self is received by the community around them, the way their online self is received, the way their work is received (online and in the physical world), the way the writer positions themselves and their work in regards to the hashtags they associate themselves with, and the way their work is surveilled by local and online authoritative bodies. Writers, then, are an assemblage of how they attempt to territorialize themselves within the communities they wish to participate, how they are received in those communities, and how they manifest in other communities through their attempt at presence in certain communities.

In the Revok vs. H\&M case participating writers' make themselves part of the discursive assemblage concerning Revok's cause by painting H\&M storefronts. In so doing they are making their graffiti a political statement and establishing themselves as informed, aggressive supporters of Revok and the rights of graffiti writers everywhere, while also presenting themselves as vehemently oppositional to H\&M. Specifically, writers are employing graffiti in the way de Carteau refers to as a tactic, which he says is "an art of the weak... [tactics] are seized opportunities of power or resistance within the domain of a more powerful regime." (de Certeau and Rendall, 1988: 37-38). Writers putting graffiti on H\&M stores serves as a tactic in two ways; one, as a protest tactic and two, as a self-promotion tactic.

Writing on H\&M stores in the particular moment of the controversy around the H\&M lawsuit against Revok served as a protest tactic for writers that made their graffiti a political act that aggressively registered their disagreement and dissatisfaction with the retailer's actions (see Fig. 4). Doing so also made writers feel like they were 'making H\&M pay' (popular comments under many images of grafffitied H\&M storefronts were 'make em pay' and 'they're gonna pay one way or another'). As Ket says, “The direct action was necessary because we live in a world where people think armchair activism is enough, but it doesn't hurt their pockets." (Ket, 2018). So, while writing graffiti on H\&M stores may have done little to get H\&M to pay writers for their work or even not steal their work, those who engaged in the acts did believe they would negatively impact (if only minorly) H\&M's corporate bottom line because the stores would have to pay to have the graffiti removed. This intentional financial inconveniencing further serves to make writing on H\&M stores a

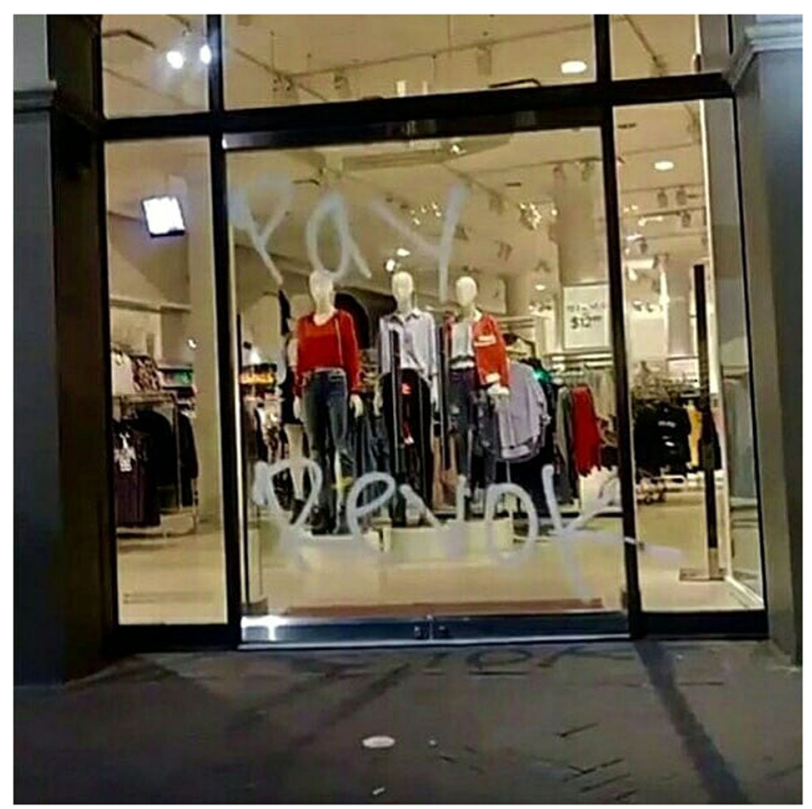

Fig. 4 'Pay Revok' spray painted on the doors of a New Orleans H\&M This figure is not covered by the Creative Commons Attribution 4.0 International License. Reproduced with permission of Instagram user lyingonthemoon1811. copyright (c) Instagram user lyingonthemoon1811, all rights reserved 
conscious political tactic and a form of contentious political participation (Waldner and Dobratz, 2013).

Of course, any act of graffiti is always-already a self-promotion tactic and the graffiti put on H\&M stores is no different. But it does more than just build a reputation for a writer and affirm them as a member of the graffiti community. It also serves as a public statement announcing the writer's dissatisfaction with $\mathrm{H} \& \mathrm{M}$ and an act that establishes these writers as particularly oppositional, assertive, and culturally aware writers within their community of graffiti writers. Additionally, it creates a particular kind of spectacle that helps communicate the Revok vs. H\&M controversy to the public by being a visual counter-hegemonic presence that immediately raises questions in the viewer about why the graffiti was placed on H\&M stores at that specific time.

\section{Conclusion}

The idea that graffiti put on H\&M stores creates a spectacle is of crucial importance, because engaging with the concept of the spectacle is what motivates graffiti writers generally, encourages their efforts to cultivate presence on social media, and provoked their writing on H\&M stores in support of Revok. Writing on H\&M stores in this particular moment and posting what they did on social media offers writers a series of reputational advantages and allows them to create, and engage with, the spectacle in a complex way.

First, the spectacle that the graffiti creates violates the existing appearance that H\&M has worked to present, namely that they are a controlled, ordered, and clean space. Second, for those aware of the situation concerning Revok and H\&M the graffiti serves as a political tactic in the form of contentious political participation (Waldner and Dobratz, 2013) that references H\&M's appropriation of Revok's work and the lawsuit they filed against him. This disrupts H\&M's ideological claim to being a business built on 'trust, respect, inclusiveness and integrity', which H\&M espouses in their corporate values ${ }^{3}$.

Third, this graffiti creates a spectacle that furthers writers' reputation in the geographical area where they did it and on social media where they display themselves by creating presence for them in both spaces. Writers collective presence is created by virtue of how they are able to they interact with and occupy position in the dialectical assemblage of physical spaces and virtual affinity spaces. The way they attempt to mediate their graffiti identity, how they write graffiti, and how they handle encounters they have in these spaces constitutes their style (Ewen, 1999).

Fourth, the narrative writers are working to construct about themselves being aggressive and anti-authoritarian to those who would disrespect and steal from graffiti culture is furthered when they write on H\&M stores. And fifth, sharing that they have written on H\&M stores at that particular moment can get a writer noticed by high status members of the graffiti community, which can dramatically increase the writer's subcultural capital (Thornton, 1996). In fact, H\&M filing the lawsuit against Revok provided a powerful moment of opportunity for graffiti writers to legitimate themselves within the graffiti community, increase their subcultural capital and present themselves as oppositional individuals willing to take action to retaliate for what the graffiti community saw as an injustice. And all they had to do to achieve this increased status, presence, and reputation was write graffiti on H\&M stores.

The question that remains, though, is 'did writing on H\&M stores have any effect on H\&M's decision to drop the lawsuit?' Ket answers this question best when he says, "It's hard to say if the direct action campaign had an impact, but I don't think H\&M would have dropped the lawsuit as quickly as they did if the direct action campaign wouldn't have happened. H\&M seems to be flexible to changing and recognizing their mistakes. There were almost no big artist chiming in, but there was the guerrilla campaign with the graffiti writers working to show them that artists have a voice and power and that you can't just rob them and attack them with lawsuits." (Ket, 2018)

Received: 27 July 2018 Accepted: 1 October 2018

Published online: 30 October 2018

\section{Notes}

1 Unless otherwise noted all dates and quotes have come from the lawsuit H\&M filed, a stable download site for the lawsuit is https://www.worldipreview.com/download? $\mathrm{id}=10078$

2 A complete timeline of the events not detailed in the lawsuit can be found here: https:// hyperallergic.com/432709/hm-lawsuit-street-artist-revok-copyright-law/

$3 \mathrm{H} \& \mathrm{M}$ corporate values can be found here: http://about.hm.com/en/career/enjoy-ourculture/more-about-our-values.html

\section{References}

Arendt H (1998) The human condition, 2nd edn. University of Chicago Press, Chicago

Castleman C (1984) Getting up: subway graffiti in New York. MIT Press, Cambridge

de Certeau M, Rendall S (1988) The practice of everyday life. University of California Press, Oakland

Deleuze G, Guattari F (1987) A thousand plateaus: capitalism and schizophrenia. University of Minnesota Press, Minneapolis

Ewen S (1999) All consuming images: The politics of style in contemporary culture. Basic Books, New York City, p 79

Ferrell J (1996) Crimes of style: urban graffiti and the politics of criminality. Northeastern University Press, Lebanon, New Hampshire

Gee JP (2005) Semiotic social spaces and affinity spaces: from The Age of Mythology to today's schools. In:Barton D, Tusting K (eds) Beyond communities of practice: language power and social context. Cambridge University Press, Cambridge, p 214-232

Habermas J (1984) The theory of communicative action. Beacon Press, Boston

Halsey M, Young A (2006) Our desires are ungovernable: writing graffiti in urban space. Theor Criminol 10(3):32

Ket A (2018) Interviewed by: Mitman T. (15 May, 2018).

Lachmann R (1988) graffiti as career and ideology. Am J Sociol 94(2):22

Mitman T (2018) The art of defiance: graffiti culture in Philadelphia. Intellect Books, Bristol/Chicago

Snyder GJ (2009) graffiti lives: beyond the tag in New York's urban underground. New York University Press, New York City

Thornton S (1996) Club cultures: music, media, and subcultural capital. Wesleyan University Press, Middletown

Waldner LK, Dobratz BA (2013) Graffiti as a form of contentious political participation. Sociol Compass 7(5):377-89

\section{Additional information}

Competing interests: The author declares no competing interests.

Reprints and permission information is available online at http://www.nature.com/ reprints

Publisher's note: Springer Nature remains neutral with regard to jurisdictional claims in published maps and institutional affiliations.

\footnotetext{
Open Access This article is licensed under a Creative Commons Attribution 4.0 International License, which permits use, sharing, adaptation, distribution and reproduction in any medium or format, as long as you give appropriate credit to the original author(s) and the source, provide a link to the Creative Commons license, and indicate if changes were made. The images or other third party material in this article are included in the article's Creative Commons license, unless indicated otherwise in a credit line to the material. If material is not included in the article's Creative Commons license and your intended use is not permitted by statutory regulation or exceeds the permitted use, you will need to obtain permission directly from the copyright holder. To view a copy of this license, visit http://creativecommons.org/ licenses/by/4.0/.
}

(C) Crown 2018 